Original article

\title{
Transmiocardial laser revascularization in combination with bone marrow cells implantation in the ischemic heart disease surgery: long-term results
}

\author{
Alexander M. Chernyavskiy, Alexey V. Fomichev, Stanislav M. Minin, Nikita A. Nikitin, Julia E. Kareva
}

National Medical Research Center n.a. E.N. Meshalkin, Novosibirsk, Russia

Received 6 July 2017, Revised 19 September 2017, Accepted 9 October 2017

C 2017, Chernyavskiy A.M., Fomichev A.V., Minin S.M., Nikitin N.A., Kareva J.E.

(C) 2017, Russian Open Medical Journal

\begin{abstract}
Background - The problem of incomplete myocardial revascularization for diffuse and distal lesions of the myocardium is still relevant. We assessed the clinical and instrumental long-term results of autologous bone marrow cell (BMC) implantation in laser channels in ischemic heart disease with diffuse and distal coronary disease.

Material and Methods - In 2007 and 2008, 35 ischemic heart disease (IHD) patients with diffuse and distal coronary disease during coronary artery bypass grafting (CABG) underwent BMC implantation in laser channels in the clinic of National Medical Research Center n.a. E.N. Meshalkin (Novosibirsk, Russia). This group was named as "BMC group". The Control group consisted of 29 patients who underwent only CABG. Clinical and instrumental assessment of the method's effect was carried out at two weeks, six months, and six years after surgery. Long-term follow-up was performed only in 30 patients from the BMC group.

Results - After six months postoperatively, the severity of angina and heart failure based on Canadian Cardiovascular Society functional class (CCS FC) and the New York Heart Association functional class (NYHA FC) was significantly less in the BMC group than in the Control group ( $p=0.03$ for CCS FC and $p=0.04$ for NYHA FC). Six years after surgery angina and heart insufficiency were at the same level. According to perfusion scintigraphy, there was a slight decrease of stable perfusion defects (SPD) in the immediate postoperative period and a more pronounced SPD reduction at six months after surgery. In BMC group, the SPD value before surgery was 18.4 (12.8, 22.4$) \%, 16.1$ (11.6, $19.3) \%$ at two weeks after the operation, and $13.2(8.5,17.3) \%$ after six months. In the long-term period (six years), SPD was 11.9 (8.7, $14.2) \%(p=0.047)$. A similar pattern was observed in the analysis of transient perfusion defects: baseline was $29.3(22.1,34.1) \%, 13.1$ $(11.2,16.5) \%$ at six months, and $17.0(14.3,20.5) \%$ in the long term $(p=0.047)$. Left ventricular ejection fraction before surgery was $51(49$, $57) \%, 54(49,57) \%$ at two weeks after the operation, $54(49,58) \%$ at six months, and $52(49,58) \%$ after six years. The dynamics are not statistically significant ( $p=0.068$ ).

Conclusion - Autologous BMC implantation in laser channels is an effective method of IHD surgical treatment if it is impossible to perform direct myocardial revascularization. The indirect revascularization effect is formed in the first six months after surgery and remains at the same level for six years.
\end{abstract}

Keywords: bone marrow stem cell, myocardial infarction, transmyocardial laser revascularization, coronary artery bypass grafting.

Cite as Chernyavskiy A, Fomichev A, Minin S, Nikitin N, Kareva J. Transmiocardial laser revascularization in combination with bone marrow cells implantation in the ischemic heart disease surgery: long-term results. Russian Open Medical Journal 2017; 6: e0410.

Correspondence to Alexey V. Formichev. Address: Rechkunovskaya str., 15, Novosibirsk, 630055, Russia. Phone: +7 (913) 4872965.

E-mail:a_fomichev@list.ru

\section{Introduction}

Ischemic heart disease (IHD) remains the most significant problem of the world health system. Despite the apparent progress in the medical and surgical treatment of IHD, morbidity, hospitalization, and mortality have not decreased [1]. The problem of incomplete myocardial revascularization for diffuse and distal lesions of the myocardium, with small-diameter coronary vessels (less than $1 \mathrm{~mm}$ ), is still relevant, because all revascularization methods used at present are effective in arterial diameter of 1.5 $\mathrm{mm}$ and a good distal arterial pool [2].

Currently, alternative methods of revascularization, including development of laser and stem cell technologies, are receiving attention [1]. New cell products and stem cell delivery methods in the myocardium have been developed [3]. However, at the moment there is no consensus about the advantages of such methods and their contribution to the processes of angiogenesis and vasculogenesis. Despite the many publications about stem cell therapy in the treatment of IHD [3], there are a limited number of publications about the long-term results of indirect myocardial revascularization $[3,4]$.

The aim of this study was to assess the clinical and instrumental long-term results of autologous bone marrow cell (BMC) implantation in laser channels in IHD patients with diffuse and distal coronary disease. 

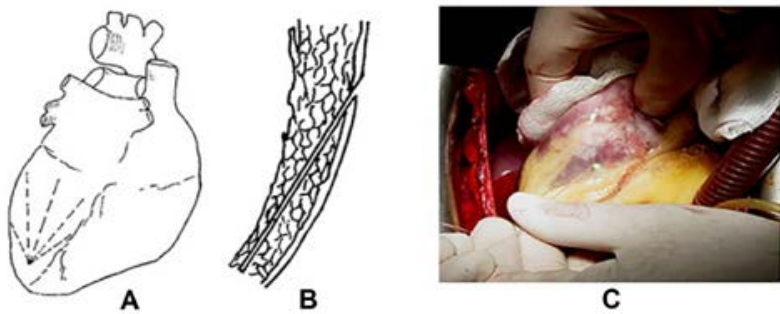

Figure 1. Laser channel formation. A - laser channel layout; B - scheme of intra-blind myocardial laser channel in the wall of the left ventricle; $C$ Laser channel formation.

\section{Material and Methods}

Institutional Review Board and Ethics Committee approval was obtained before performing our prospective research analysis. All the patients gave their informed consent before taking part in a study.

In 2007 and 2008, 35 IHD patients with diffuse and distal coronary disease during coronary artery bypass grafting (CABG) underwent $B M C$ implantation in laser channels in the clinic of National Medical Research Center n.a. E.N. Meshalkin (Novosibirsk, Russia). This group was named as "BMC group".

Exclusion criteria included: i) associated cardiac pathology that requires surgical correction, ii) detection of malignant tumors in the last 5 years, iii) vascular proliferative diseases (diabetic retinopathy, arteriovenous malformations, hemangiomas), iv) left ventricular ejection fraction (LVEF) $<30 \%$.

The Control group consisted of 29 patients. All patients in this group underwent only direct myocardial revascularization - CABG (problematic arteries did not undergo bypass grafting). The average age of patients was $58.5 \pm 7.3$ years (mean with standard deviation); $97.1 \%$ of the patients were men, mostly (60\%) aged 50 to 60 years.

To determine the angina functional class (FC) we used the Canadian Cardiovascular Society (CCS) classification. All the patients arrived at the clinic with an initially high CCS degree of angina: grade III or IV. The patients distribution relative to the New York Heart Association (NYHA) in the main group: FC II -9 patients, FC III -21 patients; in the control group - FC II-9 patients, FC III -20 patients.

According to the medical history, 52 patients had myocardial infarction at different times prior to surgery $181.3 \%$ of the patients), confirmed by the clinical and instrumental methods of research. Twenty-one patients (32.8\%) had a history of two or more heart attacks. Eight patients (12.5\%) had a history of postinfarction left ventricular aneurysm.

Eleven patients (17.1\%) had significant atherosclerosis of another vascular pool and one patient (1.56\%) had signs of multifocal atherosclerosis. Six patients $(9.37 \%)$ had a defeated brachiocephalic artery and one patient (1.56\%) had Leriche's syndrome. Comorbidities were arterial hypertension in 55 patients (85.93\%) and diabetes of varying severity in four patients (6.25\%). Three patients (4.68\%) had cerebrovascular accidents and one had vascular encephalopathy. Three patients $(4.68 \%)$ had premature ventricular beats, one had supraventricular beats, and one had atrial fibrillation.

Indications for surgery were: i) severe angina refractory to clinical antianginal therapy, ii) diffuse coronary artery lesion of the distal bed or small coronary vessel diameter (less than $1 \mathrm{~mm}$ ), or iii) a viable (hibernating) myocardium.

Twenty-four patients had one coronary endarterectomy $(37.5 \%)$, three patients had endarterectomy of two coronary arteries (4.68\%), and two patients had endarterectomy of three arteries (3.12\%). When CABG of any artery was not indicated, only mononuclear cell implantation of autologous bone marrow in the laser channels was carried out or revascularization was not performed. It should be noted that most often a combination of several types of coronary lesions took place, which did not allow us to perform direct myocardial revascularization.

One of the main conditions of the operation was the presence of a viable myocardium in the revascularization area [1]. In this regard, we analyzed two-staged myocardial scintigraphy with Tc-99 data for myocardial viability, as well as to assess the effectiveness of indirect revascularization. The status of the infarction was assessed on a 5point scale: 4 - rule; 3 - ischemia (hibernating myocardium); 2 small focal scarring; 1 -tripe; 0 -aneurysm.

The main parameters were stable perfusion defect (SPD, \%) and transient perfusion defect (TPD,\%).

One of the main instrumental methods was echocardiography and tissue dopplerography. Attention was paid to left ventricular function, the presence or absence of violation of local contractility and strain rate dynamics. Also we assessed angina CCS FC and NYHA FC dynamics.

Follow-up care of discharged patients occurred at two weeks, six months and six years after surgery. Long term follow-up (six years after the operation) was performed in 30 patients from the first group. Four patients were not followed long term due to patient refusal to travel long-distance to the clinic. One person died due to oncological reasons. All patients in the control group (29 patients) were examined in the long term.

After induction of anesthesia and tracheal intubation, bone marrow aspiration was performed through the rear iliac spine puncture. The amount of bone marrow aspirate was $50 \mathrm{ml}$. Aspirate was stored in a sterile vial with heparinized saline with an aspirate: saline ratio of 1:3 to a final concentration of 50 units of heparin, in $1 \mathrm{ml}$. During CABG, the BMC was prepared in a specialized laboratory. The principle of the isolating the cell material method was based on the difference in the density of blood cells. A mixture of Ficoll and radiopaque substances izopak (verografin) created a density gradient, allowing marrow cells to split by centrifugation at mononuclear fraction, which included lymphocytes, monocytes, a subpopulation, hematopoietic blast cells from a fraction containing granulocytes, and erythrocytes.

After we performed the distal anastomoses, three radially arranged blind laser channels were formed (Figure 1). Laser was applied in pulsed mode, with a pulse duration of $20 \mathrm{~ms}$ and an interval between pulses of $20 \mathrm{~ms}$. The radiation power was 10 watts. Channel length was determined by the size of scar area. Further, in order to create a closed cavity in the channel mouth, an $\mathrm{n}$-stitch was superimposed, the BMC infusion was performed, and the $\mathrm{n}$-stitch arose (Figure 2).

Due to the small number of observations in the sample, we used nonparametric data. Descriptive characteristics are presented as median (first quartile, third quartile). In Figures 3-6, data presented as median. To determine the significance of differences of paired comparisons, we used Wilcoxon's test. When comparing the number of dependent samples (result of treatment at different times) to apply Friedman's analysis of variance (ANOVA). For the statistical analysis of categorical indicators, Fisher's exact test was used. A p-value of $\leq 0.05$ was considered statistically significant. 


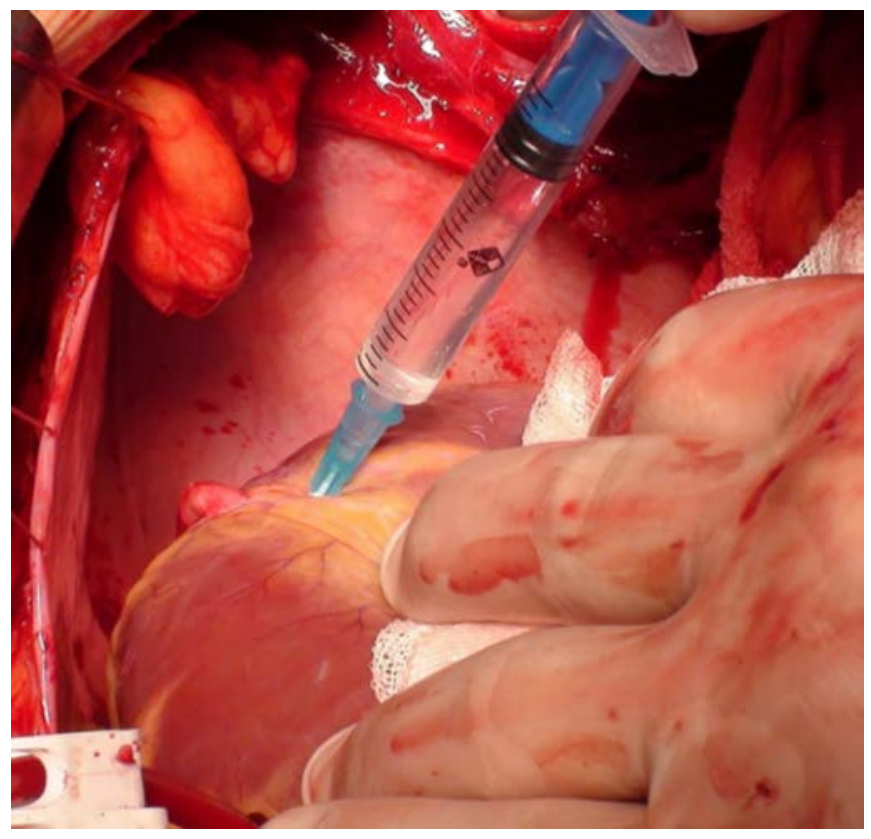

Figure 2. Bone marrow cell implantation

\section{Results}

The procedure for sampling bone marrow aspirate was well tolerated, and no bleeding and hematoma were found. No disturbances of cardiac rhythm in the postoperative period were revealed. At the final stage of the operation, after the cessation of the occlusion of the aorta in all patients, we noted an independent restoration of cardiac activity. After six months postoperatively, the severity of angina and heart failure based on CCS FC and NYHA FC was significantly less in BMC group than in Control group ( $p=0.03$ for CCS FC and $p=0.04$ for NYHA FC). Six years after surgery angina and heart insufficiency were at the same level.

The dynamics of SPD, reflecting irreversible scarring of the myocardium and partially hibernating myocardium, were as follows. In BMC group there was a slight SPD decrease in the immediate postoperative period, and a more pronounced SPD reduction in the long term period. SPD value in BMC group before the operation was $18.4(12.8,22.4) \%, 16.1(11.6,19.3) \%$ at two weeks after the operation, and $13.2(8.5,17.3) \%$ after six months (according to Friedman's ANOVA, $\mathrm{p}=0.005$ ). At six years, the SPD value was not significantly changed: $11.9(8.7,14.2)$ (Figure 3). Such dynamics indicate an increase in the microcirculatory myocardial reserve, which occurs during the first six months (Figure 3). There were no reliable dynamics for time points after that. The Control group showed a significant SPD decrease after two weeks after the surgery due to CABG, and after six months the SPD remained at the same level.

Dynamics of the TPD defining myocardial hypoperfusion appearing during exercise, has a similar character (Figure 4). Initially, the TPD value in the BMC group was $26.1(22.4,28.2) \%$, $13.4(10.2 .15 .2) \%$ at six months, and $17.3(14.8,19.4) \%$ after six years. In the Control group, the value of the TPD before surgery was $27.1(23.4,31.2) \%, 21.2(19.2,23.8) \%$ after six months, and $23.0(21.3,25.1) \%$ after six years.

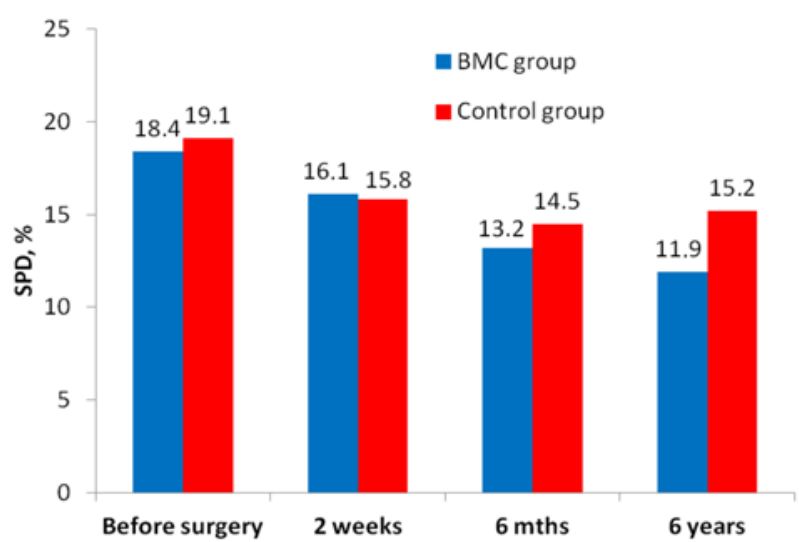

Figure 3. The dynamics of stable perfusion defects (SPD)

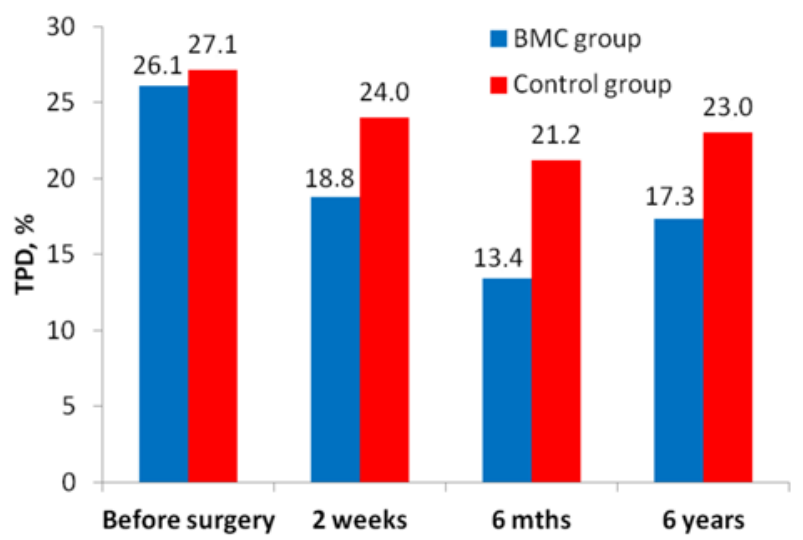

Figure 4. The dynamics of transient perfusion defects (TPD)

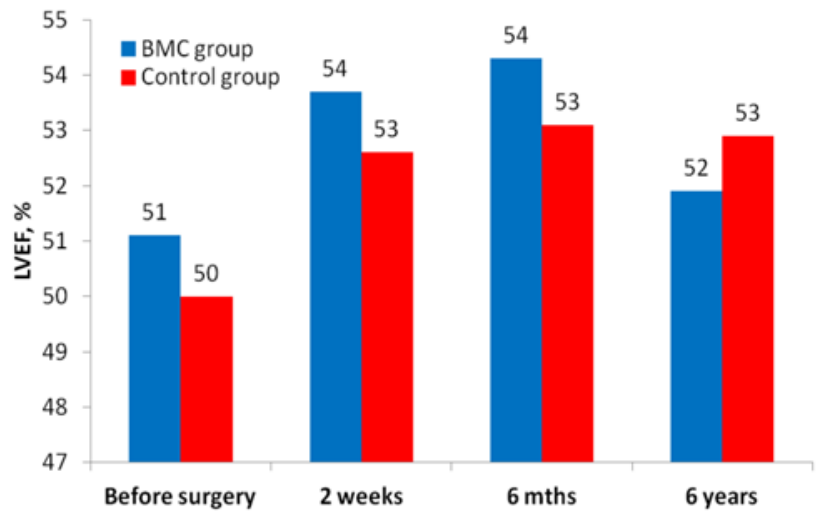

Figure 5. The dynamics of left ventricular ejection fractions (LVEF)

Left ventricle global contractility assessment in the $\mathrm{BMC}$ group revealed moderate and reliable LVEF improvement within six months after surgery, and no significant dynamics were observed six years after surgery. The LVEF prior to surgery was $51(49,57) \%, 54(49,57)$ $\%$ at two weeks after the operation, $54(49,58) \%$ at six months, and $52(49,58) \%$ in the long-term period (six years) (Figure 5$)$. In the Control group, the LVEF almost did not change, remaining at the same value in the long term period, which contrasts with the significant increase in LVEF in the BMC group. LVEF before the operation was 50 $(46,54) \%, 53(49,56) \%$ at two weeks after the operation, $53(50,56)$ $\%$ at six months, and $53(50,55) \%$ at six years after surgery. 


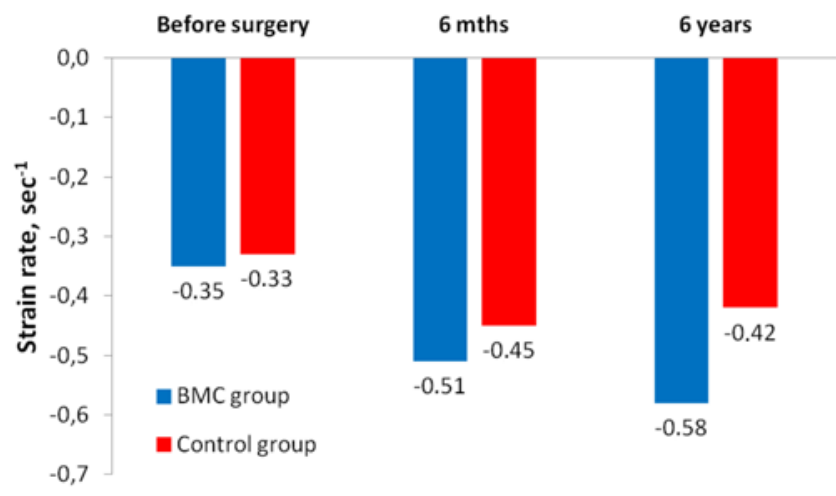

Figure 6. The dynamics of left ventricle strain rate $\left(\mathrm{sec}^{-1}\right)$

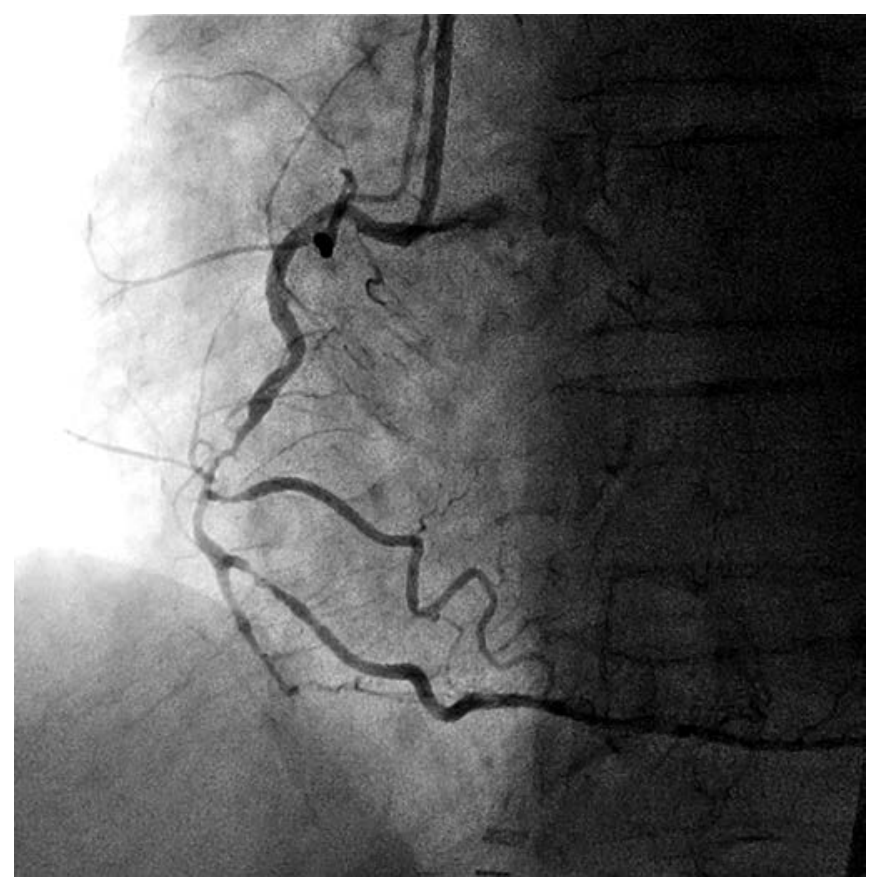

Figure 7. Coronary angiography before surgery. Patient $\mathrm{H} ., 67$ years old, 2009.

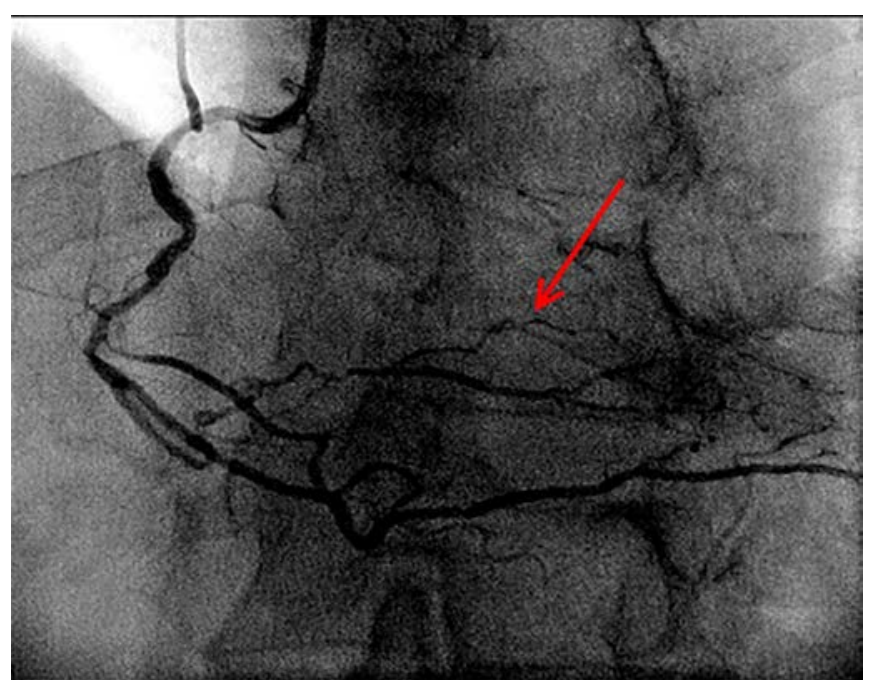

Figure 8. Coronary angiography after BMC implantation in laser channels. Patient $\mathrm{H}$., 67 years old, 2015. The arrow indicates a collateral network (aortocoronary bypass grafts are occluded).
In BMC group, the number of akinetic segments both before surgery and in the immediate postoperative period was 2.1 (1.7, $2.5)$, and $1.9(1.6,2.1)$ at six months after surgery (the difference among the groups is statistically significant: $p<0.010$, according to Friedman's ANOVA). In the long term, it was not statistically significant, $1.8(0.6,1.9)$. In the Control group, there was a significant decrease in the number of akinetic segments in the immediate postoperative period; values afterward remained at the same level. It was $2.4(2.2,2.7)$ before surgery, $1.7(1.4,1.9)$ at six months after surgery, and $2.1(1.7,2.3)$ after six years.

The numbers of hypokinesis segments before surgery and in the immediate postoperative period in the BMC group were 0.44 $(0.41,0.47)$ and $0.8(0.72,0.91)$ in six months after surgery. The statistical significance of differences within the group, according to Friedman's ANOVA, $p=0.760$. The differences were not reliable. At follow-up examination after six years, there were no reliable dynamics compared with the preoperative data: $0.80(0.72,0.88)$. The dynamics of the hypokinetic segments in the Control group were also not reliable.

There were no reliable dynamics for tissue dopplerography data in both groups. Strain rate before surgery in the BMC group was $-0.35(-0.38,-0.31)$, at six months after surgery $-0.51(-0.53$, $0.48)$, and $-0.58(-0.61,-0.55)$ at six years after surgery. The statistical significance of differences within the group (according to Friedman's ANOVA, $p=0.08$ ). Initially, the strain rate value in the Control group was $-0.33(-0.36,-0.33)$, at six months after surgery $0.45(-0.48,-0.41), p=0.12$ (Figure 6).

It should be noted that for patients who underwent control coronary angiography in some cases in the long term period, there was a more pronounced network of collaterals and flows compared with preoperative data in indirect revascularization patients (Figures 7 and 8).

\section{Discussion}

This article presents the results of six-year follow-up of patients who underwent coronary bypass surgery and transmyocardial laser revascularization, combined with implantation of autologous bone marrow mononuclear fraction. We used 29 patients after CABG as a Control group. We analyzed the clinical status of the patients, the dynamics of myocardial contractility, and local contractility of the left ventricle on echocardiography, as well as myocardial perfusion changes according to perfusion scintigraphy six months after surgery. There was improvement in both total perfusion and perfusion at the site of the impact of indirect revascularization; and we noted some improvement in global myocardial contractility. Segmental contractility showed a significant decrease in the number of akinetic segments; the number of hypokinetic segments was not significantly changed. For a further period of observation there were no reliable parameter dynamics. In the control group, positive dynamics were observed in the immediate postoperative period; in six months and six years after the operation, the parameters remained at the same level.

The 1960s was marked by the rapid development of CABG; however, despite the great success in the treatment of ischemic heart disease patients, surgeons are once again faced with the unresolved problem of myocardial revascularization. In $25-30 \%$ of cases, coronary vessel diameter is insufficient for effective direct myocardial revascularization. Moreover, diffuse and distal coronary artery lesions result in bypass grafting refusal. There is 
also a challenge of repeated CABG and multiple coronary angioplasty and stenting [5]. Thus, there is a significant group of patients who are ineligible for traditional methods of direct revascularization. These conditions have determined the alternative methods of myocardial revascularization development.

Laser technology, in conjunction with BMC implantation, is a safe procedure, which improves the quality of life one year after the surgery [2]. Perfusion scintigraphy showed decrease of perfusion defects in the revascularization areas within one year after the procedure. Channels created by laser remain open and perfused myocardium protects against ischemia, and these are reliable reservoirs for BMC. The first histological data on the crosschannel were introduced by Mirhoseini [6, 7]. He and his colleagues reported on channels remaining open within two years after the operation. Later, Okada et al. [8] reported about maintaining patency of the channel within a few years after the operation. Our experimental results showed the formation of connective tissue in the areas of laser exposure within three months after surgery with large vascular formation, larger than $1000 \mathrm{~mm}$., as well as large-walled sinusoidal type vascular formation of smaller dimensions. These vessels are unique in the intact myocardium.

The question of stimulated angiogenesis, according to the literature, has no single point of view. Our data are consistent with those of Malekan et al. [9] about a non-specific tissue reaction on myocardium damage. Our results showed that comparison of transmyocardial laser revascularization with a computer aided design model by level myocardial revascularization revealed the same level of density-sectional dimensions of the vessel as 40 $\mathrm{mcm}$ to $300 \mathrm{mcm}$ [2]

In recent years, BMC and techniques of myocardial laser revascularization are the subjects of research around the world. Numerous authors [10-13] confirm that regional BMC is competent in restoring ischemic myocardium microvasculature and, likely, fix myocardial defects by functioning cardiac myocytes, which leads to a decrease in angina class and partial recovery of cardiac contractility. In this study, we investigated the possibility of $\mathrm{BMC}$ to differentiate into cardiomyocytes, with an emphasis on neovascularization in the ischemic myocardium and formation of de novo vessels, without cambial elements of pre-existing vasculature vasculogenesis and prospects for a long term period.

There is an insufficient number of publications on BMC therapy and laser revascularization. Available data include mostly one-year results that show an improvement in heart function [3, 14]. Also, there is convincing evidence about stem cell implantation techniques and the impact of laser revascularization on blood perfusion and myocardial contractile function [4, 14]. However, most of these studies evaluated perfusion periods that did not exceed 1-2 years. There are still many questions. What is the effectiveness period for indirect revascularization? When does the vasculogenesis peak come after revascularization? When it is necessary to assess the effect of the operation? Currently, this topic has not been studied enough, and the results are contradictory.

The small sample size does not allow global conclusions on the effectiveness of bone marrow cells. There is no clear understanding of the required cell number, and the part of the cells that persist in the myocardium. The effect of laser exposure on the combined method of indirect revascularization is unknown. Research aimed at addressing these scientific tasks will improve the efficiency of cellular technologies in IHD surgery. We believe that our results suggest a cumulative effect of laser revascularization and cell therapy, improving the surgical treatment results of coronary artery disease in the near and long term period. It is worth noting that local perfusion and contractility in the long term does not deteriorate, even in the event of coronary grafts dysfunction. However, we believe that there is need of data accumulation, as well as research aimed at identifying new technologies of indirect revascularization and ways of improving the potential properties of BMC for enhancing longterm results.

\section{Conclusion}

Summarizing all the above, we can conclude that the implementation of direct revascularization of the ischemic myocardium in the early postoperative period leads to myocardial perfusion improvement, and remains at that level for six years, which is what we saw in the control group of patients. Regarding the patients who underwent CABG in conjunction with $B M C$ implantation in laser channels, the operation has a two-stage impact on myocardial perfusion. Myocardial perfusion improvements in the few days after surgery resulted from direct revascularization, as well as the development of neoangiogenesis and vasculogenesis in the hibernate area as reduction of perfusion defects was revealed over the next six months due to BMC implantation in laser channels. Despite the satisfactory results of indirect revascularization, the need for new indirect myocardial revascularization technologies development is clear.

\section{Ethical approval}

All procedures performed in studies involving human participants were in accordance with the ethical standards of the institutional research committee and with the 1964 Helsinki declaration and its later amendments or comparable ethical standards.

\section{Funding}

This study was funded by a Russian Scientific Foundation grant (project no. 16-15-00057).

\section{Conflict of Interest}

The authors declare that they have no conflict of interest.

First results of this study was reported in Proceedings of the XXV Conference on High-Energy Processes in Condensed Matter (HEPCM 2017): Dedicated to the 60th anniversary of the Khristianovich Institute of Theoretical and Applied Mechanics Siberian branch of Russian Academy of Sciences (5-9 June 2017, Novosibirsk, Russia) [16]

\section{References}

1. Kliver EN, Cherniavsky AM, Pokushalov EA, Romanov AB, Terekhov IN. 3-year outcomes of endocardial implantation of autologous bone marrow mononuclear cells in cad patients with normal ejection fraction value. Circ Path Card Surg 2015; 19(1): 59-65. Russian. https://elibrary.ru/item.asp?id=23763682.

2. Chernyavsky AM, Fomichev AV, Chernyavsky MA, Larionov PM, Bondar VU, Sergeevichev DS. Comparative estimation of indirect revascularisation efficacy in IHD surgery. Circ Path Card Surg 2013; (1): 15-20. Russian. https://elibrary.ru/item.asp?id=18881280.

3. Xiao C, Zhou S, Liu Y, Hu H. Efficacy and safety of bone marrow cell transplantation for chronic ischemic heart disease: a meta-analysis. Med Sci Monit 2014; 20: 1768-1777. https://doi.org/10.12659/MSM.892047. 
4. Gyongyosi M, Wojakowski W, Lemarchand P, Lunde K, Tendera M, Bartunek J, et al. Meta-analysis of cell-based caRdiac stUdiEs (ACCRUE) in patients with acute myocardial infarction based on individual patient data. Circ Res 2015; 116(8): 1346-1360. https://doi.org/10.1161/CIRCRESAHA.116.304346.

5. Burakovsky VI. First Steps. Notes of a heart surgeon. Moscow, Russia: Medicine-Znanie, 1988. Russian.

6. Mirhoseini M, Cayton M, Shelgikar S, Fisher J. Clinical report: laser myocardial revascularization. Lasers Surg Med 1986; (6): 459-461. https://doi.org/10.1002/Ism.1900060507.

7. Mirhoseini M, Clayton MM. Revascularization of the heart by laser. $J$ $\begin{array}{lll}\text { Microsurg } & \text { 2(4): 253-260. }\end{array}$ https://www.ncbi.nlm.nih.gov/pubmed/7310316

8. Okada M, Ikuta H, Shimizu K, Horii H, Nakamura K. Alternative method of myocardial revascularization by laser: experimental and clinical study. Kobe J Med Sci 1986; 32(5): 151-161. https://www.ncbi.nlm.nih.gov/pubmed/3821017.

9. Malekan R, Reynolds C, Narula N, Kelley S, Suzuki Y, Bridges C. Angiogenesis in transmyocardial laser revascularization. A nonspecific response to injury. Circulation 1998; 98(19 Suppl): II62-II65. https://www.ncbi.nlm.nih.gov/pubmed/9852882.

10. Konstanty-Kalandyk J, Piątek J, Miszalski-Jamka T, Rudziński P, Walter $Z$, Bartuś K, et al. The combined use of transmyocardial laser revascularisation and intramyocardial injection of bone-marrow derived stem cells in patients with end-stage coronary artery disease: one year follow-up. Kardiol Pol 2012; 71(5): 485-492. https://doi.org/10.5603/KP.2013.0095.

11. Allen KB, Kelly J, Borkon AM, Stuart RS, Daon E, Pak AF, et al. Transmyocardial laser revascularization: from randomized trials to clinical practice. A review of techniques, evidence-based outcomes, and future directions. Anesthesiol Clin 2008; 26(3): 501-519. https://doi.org/10.1016/j.anclin.2008.04.001.

12. Briones E, Lacalle JR, Marin-Leon I, Rueda JR. Transmyocardial laser revascularization versus medical therapy for refractory angina. Cochrane Database Syst Rev 2015; (2): CD003712. https://doi.org/10.1002/14651858.CD003712.pub3.

13. Yang SS, Li WM, Yin LL, Li Y, Fan Y, Han W, et al. Chronic effects of percutaneous transmyocardial laser revascularization in patients with refractory angina. Zhonghua Xin Xue Guan Bing Za Zhi 2007; 35(1): 5154. https://www.ncbi.nlm.nih.gov/pubmed/17386166.

14. Babin-Ebell J, Sievers HH, Charitos El, Klein HM, Jung F, Hellberg AK, et al. Transmyocardial laser revascularization combined with intramyocardial endothelial progenitor cell transplantation in patients with intractable ischemic heart disease ineligible for conventional revascularization: preliminary results in a highly selected small patient cohort. Thorac Cardiovasc Surg 2010; 58(1): 11-16. https://doi.org/10.1055/s-0029-1186199

15. Klein HM, Assmann A, Lichtenberg A, Heke M. Intraoperative CD133+ cell transplantation during coronary artery bypass grafting in ischemic cardiomyopathy. Multimed Man Card Thorac Surg 2010; 2010(809): mmcts. 2009.003947. https://doi.org/10.1510/mmcts.2009.003947.

16. Chernyavskiy AM, Fomichev AV, Minin SM, Nikitin NA. Bone marrow mononuclear cell implantation in myocardial laser channels in the ischemic heart disease surgery. Long-term results. AIP Conference Proceedings 2017; 1893(1): 020020. https://doi.org/10.1063/1.5007458.

\section{Authors:}

Alexander M. Chernyavskiy - MD, DSc, Professor, Head of the Center of Aorta, Coronary and Peripheral Arteries Surgery, National Medical Research Center n.a. E.N. Meshalkin, Novosibirsk, Russia. http://orcid.org/0000-0001-9818-8678.

Alexey V. Fomichev - MD, PhD, Cardiovascular Surgeon, Department of Aorta and Coronary Arteries Surgery, National Medical Research Center n.a. E.N. Meshalkin, Novosibirsk, Russia. http://orcid.org/0000-0001-8576$\underline{9617}$.
Stanislav M. Minin - MD, PhD, Head of the Radioisotope Diagnosis Department, National Medical Research Center n.a. E.N. Meshalkin, Novosibirsk, Russia. http://orcid.org/0000-0001-6626-6408.

Nikita A. Nikitin - MD, Radiologist, Radioisotope Diagnosis Department, National Medical Research Center n.a. E.N. Meshalkin, Novosibirsk, Russia. http://orcid.org/0000-0001-5643-9109.

Julia E. Kareva - MD, PhD, Cardiovascular Surgeon, Department of Aorta and Coronary Arteries Surgery, National Medical Research Center n.a. E.N. Meshalkin, Novosibirsk, Russia. http://orcid.org/0000-0002-7787-4692. 